\title{
Current sheet flapping in the near-Earth magnetotail: peculiarities of propagation and parallel currents
}

\author{
Egor V. Yushkov ${ }^{1,2}$, Anton V. Artemyev ${ }^{1,3}$, Anatoly A. Petrukovich ${ }^{1}$, and Rumi Nakamura ${ }^{4}$ \\ ${ }^{1}$ Space Research Institute, 84/32 Profsoyuznaya st., Moscow, 117997, Russia \\ ${ }^{2}$ Faculty of Physics, Lomonosov University, Leninskie Gory, Moscow, 119991, Russia \\ ${ }^{3}$ Department of Earth, Planetary, and Space Sciences and Institute of Geophysics and Planetary Physics, University of \\ California, Los Angeles, California, USA \\ ${ }^{4}$ Space Research Institute (IWF), AAS, Graz, Austria \\ Correspondence to: Egor V. Yushkov (yushkov.msu@mail.ru)
}

Received: 9 March 2016 - Revised: 22 July 2016 - Accepted: 31 July 2016 - Published: 13 September 2016

\begin{abstract}
We consider series of tilted current sheet crossings, corresponding to flapping waves in the near-Earth magnetotail. We analyse Cluster observations from 2005 to 2009, when spacecraft visited the magnetotail neutral plane near $X \in[-17,-8], Y \in[-16,-2] R_{\mathrm{E}}$ (in the GSM system). Large separation of spacecraft allows us to estimate both local and global properties of flapping current sheets. We find significant variation in flapping wave direction of propagation between the middle tail and flanks. Th series of tilted current sheets represent the system of periodic, almost parallel currents with typical thickness of current filaments about $L=0.4 R_{\mathrm{E}}$. The earthward gradients of $B_{z}$ magnetic field are reduced within this current system in comparison with the gradients in the quiet near-Earth magnetotail. The wavelength (i.e. a distance between two crossings of current sheets with the same orientations) of the flapping waves is larger than $2 \pi L$ for most of observations. The velocity of flapping wave propagation is about ion bulk velocity and is significantly lower than the velocity of ion drift relative to electrons. We discuss possible drivers of flapping and estimate the amplitude of the total parallel current generated by flapping waves.
\end{abstract}

Keywords. Magnetospheric physics (magnetotail)

\section{Introduction}

The magnetotail current sheet (CS) is the key element of the Earth magnetosphere. In the tail, processes of magnetic energy dissipation and charged particle acceleration initialise the storms and substorms (Baker et al., 1996; Angelopoulos et al., 2008). Dynamical properties of the magnetotail CS (e.g. the reconnection of stretched magnetic field lines, or CS bending and oscillations) have been thoroughly studied starting from the 1960s (see reviews by Lui, 2004; Schindler, 2006; Treumann and Baumjohann, 2013; Zelenyi and Artemyev, 2013; and references therein). Flapping, how it is recognised now, is one of the most widespread types of CS activity (e.g. Zhang et al., 2002; Sergeev et al., 2004). However, other manifestations of CS dynamics (e.g. earthward plasma flows with dipolarisation fronts, formation of plasmoids) are also observed (Sharma et al., 2008; Baumjohann et al., 2007). One can distinguish two kinds of flapping motion: the vertical oscillations of the quasi-horizontal CSs (when the normal $N$ to the CS plane is basically along the $z$ axis, $\left|N_{z}\right|>0.8$, and kink-like waves do not propagate) and formation of tilted CSs (when the normal is significantly tilted, $\left|N_{z}\right|<0.8$, and kink-like waves can propagate along the dusk-dawn direction) (see details of this classification in Rong et al., 2015). These tilted CSs propagate toward the magnetotail flanks and represent a nonlinear wave-like perturbations (i.e. the perturbation amplitude is comparable with a background magnetic field) of the main magnetic field component $B_{x}$ (hereafter we use the GSM coordinate system). Observations and analysis of the flapping motion help 
to restore CS spatial profiles (e.g. Sergeev et al., 1998; Runov et al., 2012), investigate Hall electric field configuration in CSs (Wygant et al., 2005; Vasko et al., 2014), and test numerical models of CS instability (e.g. Karimabadi et al., 2003b; Sitnov et al., 2006; Zelenyi et al., 2009; Nakamura et al., 2009). The opportunity of four-spacecraft measurements of magnetic field provided by the Cluster mission was actively used to investigate details of the CS flapping (Runov et al., 2005a; Petrukovich et al., 2006, 2008; Rong et al., 2010).

The main statistics of the CS flapping at distances $|X|>$ $15 R_{\mathrm{E}}$ were collected during the first four years (2001-2004) of the Cluster mission (Runov et al., 2005a) and were significantly expanded by Geotail investigations in this region (Sergeev et al., 2006). Further, THEMIS (Runov et al., 2009) and Cluster/Double Star (Zhang et al., 2005) observations have confirmed the large-scale nature of the flapping motion. Cluster spacecraft separation in 2001-2004 was varied between 300 and $4000 \mathrm{~km}$. Thus, the Cluster tetrahedron resolved the local (along the normal direction to the CS plane) gradients of magnetic field in flapping CS well but could not estimate variations in CS characteristics along the magnetotail. These variations, being weak in the mid-tail, should be stronger in the near-Earth region (see case studies in Nakamura et al., 2009; Panov et al., 2012a). The strong gradients of CS parameters along the $x$ axis in this region are considered as potential drivers for CS instabilities resulting in flapping motion (Erkaev et al., 2009; Pritchett and Coroniti, 2011; Panov et al., 2012b).

In the near-Earth magnetotail the tilted CSs were first studied, using Double Star and Geotail single-spacecraft observations (Zhang et al., 2005; Sergeev et al., 2006). However, the number of observations in this region was small and properties of tilted CS flapping were not discussed. Thus, we use Cluster observations collected after 2004, when spacecraft crossed CSs at radial distances around $\sim 15 R_{\mathrm{E}}$ and the distances between spacecraft were large enough to study both the local (along the normal direction) CS configuration and the spatial gradient $\mathrm{d} B_{z} / \mathrm{d} x$, which is usually much weaker than the main cross-tail gradient $\mathrm{d} B_{x} / \mathrm{d} z$ (see, e.g., Rong et al., 2014; Artemyev et al., 2015). The spacecraft trajectories allow us to study CS flapping motion in the midnight near-Earth magnetotail edge $X \sim-15 R_{\mathrm{E}}$ and at the deep dawn flanks with $|X|,|Y| \sim(10-15) R_{\mathrm{E}}$ (throughout the paper we call both of these regions the near-Earth magnetotail).

\section{Data set and analysis techniques}

We selected 108 CS crossings from Cluster 2005-2009 observations: 18 series with about $2-10$ CS crossings in each and several individual crossings. The majority of statistics consists of observations in 2005 and 2006. In 2007 two of four Cluster spacecraft were very close to each other (in comparison with distances to another pair of spacecraft). Thus, the Cluster tetrahedron was close to triangle with the corresponding problems of estimations of magnetic field gradients
(Dunlop et al., 2002; Shen et al., 2012). In 2008 and 2009 we observe only few cases of flapping CSs (maybe due to evolution of spacecraft orbit). Table 1 shows all cases with the number of CS crossings and coordinates of the spacecraft tetrahedron centre for the first CS crossing.

We divide our statistics into two subsets: the first subset consists of individual CS crossings and the second subset consists of series of CS crossings. In all cases of our statistics the average angle between $l$ directions of maximal magnetic field variation (see description of the corresponding MVA method in Paschmann and Schwartz, 2000) obtained by four spacecraft is less than $10^{\circ}$. Using the timing technique (Runov et al., 2006) we determine the normal vector $N$, which is almost orthogonal to the $l$ direction - the average angle is larger than $80^{\circ}$. We do not use the MVA technique (see Paschmann and Schwartz, 2000, and references therein) to determine the normal $n$ direction, because for many crossings the MVA technique provides two minor eigenvalues with close values. Due to the large distances between spacecraft, we do not construct the local coordinate system (see, e.g., Runov et al., 2005b) by defining the direction of current density $\boldsymbol{j}=(c / 4 \pi)(\nabla \times \boldsymbol{B})$ by the curlometer technique (Dunlop et al., 2002).

To apply the timing technique we determine the time delays between spacecraft observations of the same magnetic field $B_{l}$. Due to the large distances, all four spacecraft often do not cross the neutral plane for a selected CS crossing, so we approximate $B_{l}$ profiles by straight lines. The time delays are defined as distances between these lines for a zero value of $B_{l}$. Then we calculate the velocity of the CS motion along the $N$ direction, $V_{N}$ and the vector $N$. The time delays are also used to determine a period of CS oscillations, $T$, as an average time interval between the nearest crossings of CSs with the same $\boldsymbol{N}$ vectors (within one series) and, correspondingly, the magnitude of the wavevector $k=2 \pi /\left(V_{N} T\right)$. Normal vector $N$ and angles $\alpha$ between two successive normal vectors $N$ within one series characterise the CS tilt. Both velocity $V_{N}$ and time intervals between neighbouring CS crossings $\delta T$ are presented in Table 1.

We use magnetic field $B_{l}=(\boldsymbol{B} \cdot l)$ to determine the boundary magnetic field value $B_{0}$ as a maximum $\left|B_{l}\right|$ value for a given CS crossing. We redefine $B_{z}$ as a value of the $z$ component of magnetic field $\boldsymbol{B}$ with subtracted projection of $B_{l}$ component to the $z$ direction. Large spacecraft separation significantly averages current density peak and does not allow us to calculate current density amplitude. However, the averaging does not change the current density direction, i.e. we can use curlometer data to estimate contributions of different current density components. Using this assumption we define the parallel current density as $\boldsymbol{j}_{\|}=(\boldsymbol{j} \times \boldsymbol{B}) /|\boldsymbol{B}|$. However, we cannot use curlometer data to estimate small-scale gradients (e.g. current sheet thinness). Thus, we also determine the timing current density $j_{\text {tmg }}=\left(c / 4 \pi V_{N}\right) \partial B_{l} / \partial t$. This estimate of the current density is more accurate than the curlometer calculation, be- 
Table 1. CS crossing characteristics: date and crossing time interval, number of CS crossings within a series, coordinates of the first CS crossing in GSM system (averaged from four spacecraft), angle $\alpha$ between two successive normal vectors (average value for entire series), $N_{x}$ and $N_{y}$ components of the normal vector, velocity $V_{N}$ for each crossing, and time delays $\delta T$ between CS crossings (averaged from four spacecraft).

\begin{tabular}{|c|c|c|c|c|c|c|}
\hline $\begin{array}{l}\text { Date \& time interval } \\
\quad \text { (yy.mm.dd) }\end{array}$ & CSs & $\begin{array}{c}(\mathrm{X}, \mathrm{Y}, \mathrm{Z}) \\
R_{\mathrm{E}}\end{array}$ & $\begin{array}{c}\alpha \\
\circ\end{array}$ & $\left(N_{x} ; N_{y}\right)$ & $\begin{array}{c}V_{N} \\
\mathrm{~km} \mathrm{~s}^{-1}\end{array}$ & $\begin{array}{l}\delta T \\
\min \end{array}$ \\
\hline 2005.07.10 01.00-03.00 & 7 & $(-9 ;-15 ;-1)$ & 42 & $(0.6 ;-0.6)$ & $45 ; 50 ; 22 ; 25 ; 36 ; 33 ; 38$ & $8 ; 21 ; 5 ; 19 ; 9 ; 7$ \\
\hline 2005.07 .17 10.30-12.30 & 8 & $(-13 ;-14 ; 1)$ & 63 & $(0.6 ;-0.6)$ & $72 ; 62 ; 30 ; 60 ; 54 ; 42 ; 22 ; 15$ & $0 ; 11 ; 0 ; 5 ; 0 ; 25 ; 11$ \\
\hline $2005.07 .2823 .00-00.30$ & 7 & $(-12 ;-11 ; 2)$ & 46 & $(0.5 ;-0.8)$ & $24 ; 15 ; 28 ; 19 ; 34 ; 33 ; 43$ & $22 ; 8 ; 17 ; 6 ; 12 ; 3$ \\
\hline 2005.08 .09 18.00-20.00 & 8 & $(-13 ;-8 ; 4)$ & 42 & $(0.5 ;-0.7)$ & $76 ; 52 ; 53 ; 30 ; 26 ; 35 ; 32 ; 48$ & $2 ; 4 ; 1 ; 7 ; 4 ; 8 ; 3$ \\
\hline 2005.08.12 10.00-12.00 & 8 & $(-16 ;-8 ; 2)$ & 67 & $(0.2 ;-0.8)$ & $23 ; 91 ; 17 ; 35 ; 24 ; 71 ; 28 ; 61$ & $3 ; 9 ; 1 ; 7 ; 3 ; 4 ; 3$ \\
\hline $2005.08 .1702 .30-05.00$ & 5 & $(-16 ;-7 ; 1)$ & 142 & $(0.1 ;-0.3)$ & $7 ; 18 ; 5 ; 14 ; 13$ & $31 ; 27 ; 16 ; 12$ \\
\hline 2005.08.19 12.00-12.30 & 2 & $(-17 ;-6 ; 2)$ & 180 & $(0.0 ;-0.1)$ & $14 ; 20$ & 5 \\
\hline 2006.07.09 02.30-03.30 & 4 & $(-9 ;-16 ;-3)$ & 31 & $(0.8 ;-0.5)$ & $24 ; 19 ; 21 ; 13$ & $0 ; 18 ; 4$ \\
\hline $2006.07 .1606 .30-08.30$ & 7 & $(-11 ;-15 ; 0)$ & 55 & $(0.7 ;-0.4)$ & $23 ; 15 ; 13 ; 16 ; 24 ; 15 ; 14$ & $16 ; 11 ; 21 ; 4 ; 29 ; 12$ \\
\hline $2006.07 .2311 .30-13.30$ & 7 & $(-13 ;-14 ; 1)$ & 60 & $(0.5 ;-0.7)$ & $24 ; 20 ; 16 ; 19 ; 17 ; 16 ; 20$ & $6 ; 11 ; 10 ; 8 ; 13 ; 13$ \\
\hline $2006.07 .2515 .00-17.00$ & 6 & $(-12 ;-12 ; 2)$ & 31 & $(0.7 ;-0.6)$ & $16 ; 20 ; 20 ; 28 ; 19 ; 22$ & $13 ; 23 ; 4 ; 20 ; 7$ \\
\hline 2007.07.29 08.00-11.00 & 8 & $(-13 ;-13 ; 1)$ & 81 & $(0.3 ;-0.6)$ & $16 ; 17 ; 13 ; 36 ; 38 ; 9 ; 23 ; 18$ & $23 ; 14 ; 14 ; 12 ; 13 ; 19 ; 10$ \\
\hline $2007.08 .1007 .00-08.00$ & 2 & $(-16 ;-10 ; 0)$ & 180 & $(0.0 ; 0.0)$ & $6 ; 13$ & 9 \\
\hline $2007.08 .2614 .00-18.00$ & 6 & $(-13 ;-5 ; 2)$ & 138 & $(0.1 ;-0.3)$ & $8 ; 10 ; 6 ; 7 ; 7 ; 6$ & $13 ; 44 ; 1 ; 23 ; 8$ \\
\hline 2007.09.05 06.00-08.00 & 4 & $(-16 ;-4 ; 0)$ & 142 & $(0.0 ;-0.3)$ & $9 ; 9 ; 13 ; 6$ & $20 ; 13 ; 13$ \\
\hline $2008.08 .1010 .00-13.00$ & 4 & $(-13 ;-10 ; 2)$ & 66 & $(0.5 ;-0.7)$ & $6 ; 12 ; 7 ; 14$ & $33 ; 51 ; 19$ \\
\hline 2008.08.15 06.00-08.00 & 5 & $(-15 ;-10 ; 0)$ & 132 & $(0.3 ;-0.3)$ & $11 ; 5 ; 10 ; 6 ; 14$ & $30 ; 19 ; 9 ; 32$ \\
\hline 2009.08.09 10.00-13.00 & 10 & $(-12 ;-12 ; 1)$ & 98 & $(0.5 ;-0.5)$ & $21 ; 54 ; 37 ; 16 ; 20 ; 37 ; 36 ; 21 ; 38 ; 32$ & $12 ; 2 ; 7 ; 1 ; 15 ; 3 ; 13 ; 24 ; 23$ \\
\hline
\end{tabular}

cause the large distances between spacecraft strongly affect the accuracy of the curlometer technique and smooth magnetic field gradients (see comparison between $j_{\text {curl }}$ and $j_{\text {tmg }}$ for one CS crossing shown in Fig. 1c). Thus, for the estimation of the CS thickness $L$ we use the timing current density amplitude: $L=(c / 4 \pi) B_{0} / j_{\mathrm{tmg}}$ (see Vasko et al., 2014). To study deformations of CS profiles we determine the standard deviation $\mathrm{d} B_{z}$ of $B_{z}$ magnetic field in each CS crossing interval. The CS configuration is verified using a standard deviation $\delta B_{z}$ of the magnetic field $B_{z}$ measured for different CS crossings within each series: small $\delta B_{z} /\left\langle B_{z}\right\rangle$ value shows that we deal with almost steady CS structures when only $B_{l} \approx B_{x}$ varies due to flapping motion.

To demonstrate the application of all listed methods, we consider one event from our dataset shown in Fig. 1. This event includes series of seven tilted CSs crossed by four Cluster spacecraft at 28 July 2005 around $(-12,-11,2) R_{\mathrm{E}}$ GSM. The average period of CSs oscillations is about $22 \mathrm{~min}$. The maximum distance between spacecraft is $\sim 1.7 R_{\mathrm{E}}$, and the minimum distance is $\sim 0.15 R_{\mathrm{E}}$. For each CS crossing from this series we determine the $l$ direction (for all four spacecraft), two estimates of the current density $j_{\text {curl }}$ and $j_{\text {tmg }}$, and CS normal velocity $V_{N}$. Deviation of the $l$ direction defined at different spacecraft does not exceed $1^{\circ}$. To determine time delays between spacecraft measurements of the same magnetic field $B_{l}$, we approximate time profiles $B_{l}(t)$ by straight lines using the least-squares method (see example in Fig. 1b). Knowing spacecraft positions and time delays, we calculate CS normal velocity $V_{N} \approx 28 \mathrm{~km} \mathrm{~s}^{-1}$. $V_{N}$ is directed along the normal to CS, and the angle between the normal direction and $l$ direction varies between 83 and $96^{\circ}$ for this event.

For each CS we calculate averaged values of the $B_{z}$ magnetic field excluding the component of $B_{z}$ directed along the $l$ direction (for series shown in Fig. 1 we obtain $B_{z} \approx$ $14,16,12,11,9,8,7 \mathrm{nT})$. We also calculate the standard deviation $\mathrm{d} B_{z}$ of $B_{z}$ for each CS crossing, e.g. $\mathrm{d} B_{z} / B_{z} \approx 0.02$ for CS crossings, shown in Fig. 1b. Knowing average $B_{z}$ values for all crossings from series, we calculate standard deviation $\delta B_{z}$ showing the difference between averaged $B_{z}$ for one CS crossing and averaged $B_{z}$ for all crossings from series $\left(\delta B_{z} /\left\langle B_{z}\right\rangle \approx 0.23\right.$ for series shown in Fig. 1). Using average values of $B_{z}$ measured by difference spacecraft, we calculate gradients $\mathrm{d} B_{z} / \mathrm{d} x, \mathrm{~d} B_{z} / \mathrm{d} y$, and $\mathrm{d} B_{z} / \mathrm{d} z$. Throughout the paper, we use the $\mathrm{d} B_{z} / \mathrm{d} x$ gradient (which for selected series is equal to $0.4,0.7,0.6,0.2,0.1,0.6,0.5 \mathrm{nT} / R_{\mathrm{E}}$ for seven CS crossings) and projection of the $\mathrm{d} B_{z} / \mathrm{d} r$ gradient onto the $l$ direction, $\mathrm{d} B_{z} / \mathrm{d} r_{l}$ (which for selected series is equal to $0.6,1.0,0.4,0.3,0.2,0.5,0.5 \mathrm{nT} / R_{\mathrm{E}}$ for seven CS crossings). Similarly, we calculate gradients $\mathrm{d} \phi / \mathrm{d} x, \mathrm{~d} \phi / \mathrm{d} y$ of angle $\phi$ between the $l$ direction and $x$ axis. These gradients characterise the evolution of the orientation of the flapping wave front.

We use both timing $j_{\text {tmg }}$ and curlometer $j_{\text {curl }}$ currents. However, due to larger distances between spacecraft, $j_{\text {curl }}$ is always underestimated and much smaller than $j_{\text {tmg }}$. Thus, we use $j_{\text {curl }}$ only to determine the portion of parallel currents, i.e. the ratio between projection of $j_{\text {curl }}$ vector onto the magnetic field direction (averaged over CS central region) and $j_{\text {curl }}$ magnitude (e.g. for selected series this ratio is equal to $0.9,-0.9,0.7,-0.9,0.9,-0.8,0.8$ for seven CS crossings). 

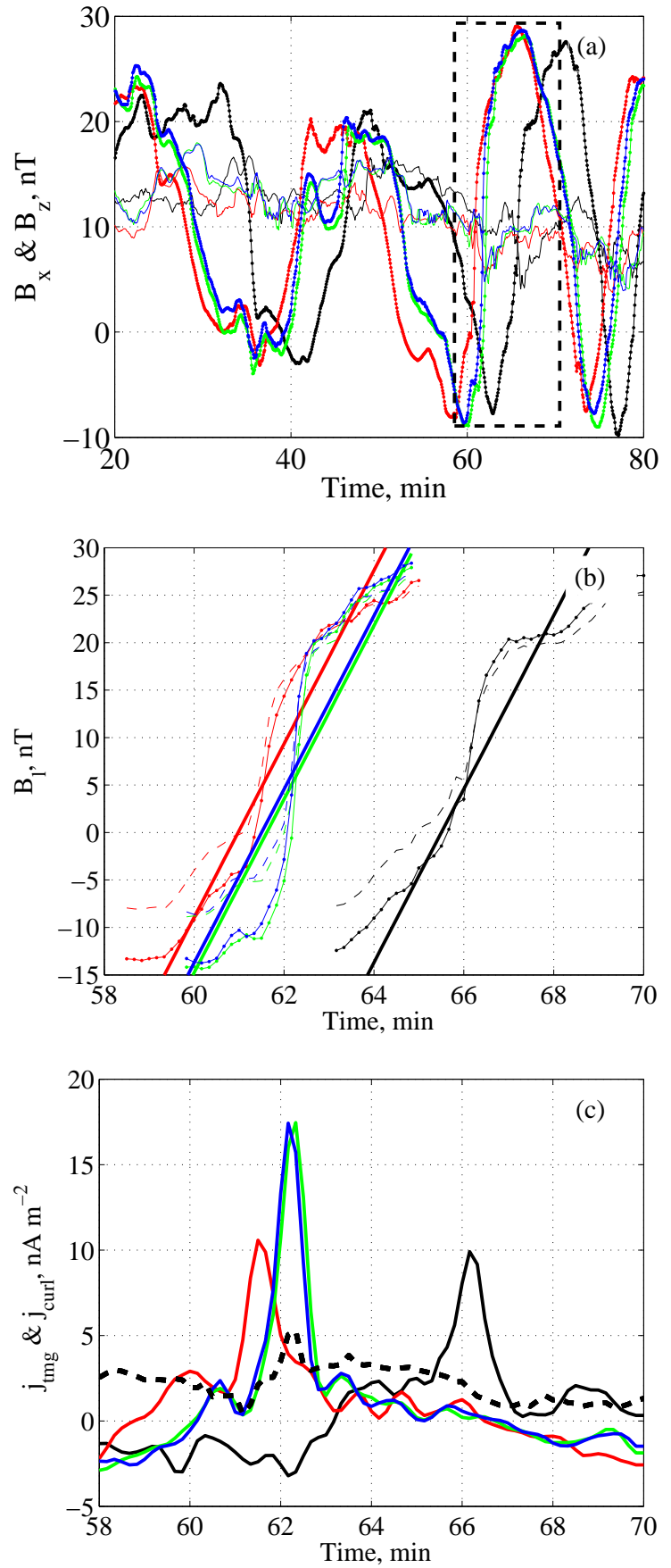

Figure 1. Data from 28 July 2005 starting from 23:00 UTC. (a) $B_{x}$ (dots) and $B_{z}$ (solid lines) fields in the series. The dash-bounded domain shows the example CS crossing. (b) Approximation of $B_{l}$ field used for calculation of time delays for the fourth crossing. (c) Amplitude of current density calculated by the curlometer method (dashed line) and the timing method $j_{\text {tmg }}$ (solid lines for four spacecraft). Cluster spacecraft colours are black (1sc), red (2sc), green (3sc), and blue(4sc).

We also calculate the value of $B_{l}$ corresponding to the maximum of $j_{\mathrm{tmg}}$ (in flapping CSs, $j_{\mathrm{tmg}}$ can maximise at some distance from $B_{l}$ reversal, e.g. for the CS crossing shown in Fig. $1 \mathrm{~b}, B_{l} \approx 6.8 \mathrm{nT}$ ). To determine CS thickness (spatial scale of current density variation) we use a ratio between $B_{l}$ amplitude, $B_{0}$, and $j_{\text {tmg }}$ magnitude. For selected series, $B_{0}$ varies from crossing to crossing within the range of 23$32 \mathrm{nT}$, whereas CS thickness $L \in[1.5,5.1] \times 1000 \mathrm{~km}$. Using the period of CS oscillations, $\mathrm{d} T$, we define a wavenumber $k \approx 2 \pi /\left(V_{N} \mathrm{~d} T\right)$ and calculate the $k L$ factor.

\section{Statistics of CS parameters}

Coordinates of all CS crossings in $(X, Y)$ and $(Y, Z)$ planes are demonstrated in Fig. 2a and b. Straight lines show the directions of the CS motion, $N$. In agreement with previous observations (Sergeev et al., 2004; Runov et al., 2005a), almost all observed CSs propagate toward the magnetosphere flank. Thus, we can interpret the $B_{x}$ magnetic field oscillations as the manifestation of wave-like disturbance propagating away from the central (midnight) region of the magnetotail. The periodic change of the $z$ component of the $N$ vector within one series of CS crossings supports this conclusion. Figure 2 shows that all waves are observed for $Y<0$ : long series of CS crossings are mostly observed for $|Y|>10 R_{\mathrm{E}}$, and small series including up to four crossings are usually observed closer to the midnight. Moreover, from Fig. $2 \mathrm{~b}$ we see that, in region $\left(|Y|<10 R_{\mathrm{E}}\right)$, almost vertical oscillations of the quasi-horizontal CSs are observed (the $N$ direction is along the $\pm z$ direction), whereas at the flank the main component of the $\boldsymbol{N}$ vector is along the $y$ direction (i.e. we deal with the dawnward propagation of titled CSs; see Table 1). Figure 2 shows that the direction of the $N$ vector varies significantly from middle tail $Y \sim 0$ to flank $|Y|>10 R_{\mathrm{E}}$. This effect was mentioned for mid-tail (Runov et al., 2005a), but in the near-Earth region it looks much more clear.

We use collected statistics of normal vectors $N$ to study the configuration of tilted CSs. For the mid-tail $\left(X \sim-18 R_{\mathrm{E}}\right)$ Petrukovich et al. (2006) showed that, in tilted CSs, the current density amplitude increases with the inclination of the neutral plane (i.e. with the growth of $\left|N_{y}\right|$ component and the decrease in the $\left|N_{z}\right|$ component). These observations were interpreted as an evidence of slip-like CS deformations (i.e the kink of the neutral plane CS without $B_{z}$ variation; Petrukovich et al., 2008; Rong et al., 2010). Indeed, the histogram in Fig. 3a demonstrates that the standard deviation of the $B_{z}$ magnetic field component from the value $\left\langle B_{z}\right\rangle$ (averaged in each series) is quite small - the averaged value $\delta B_{z} /\left\langle B_{z}\right\rangle$ is about 0.17 (both $\delta B_{z}$ and average $\left\langle B_{z}\right\rangle$ are calculated for series of CS crossings). The series with substantial $B_{z}$ variations generally include cases with monotonically decreasing of $B_{z}$ (i.e. the CS stretching events; see, e.g., Petrukovich et al., 2007). The example of significant $B_{z}$ variation is shown in Fig. 1, where a gradual decrease in $B_{z}$ is noticeable. Therefore, we can conclude that there are no periodic (or quasi-periodic) perturbations of $B_{z}$ with amplitudes larger than $0.2 B_{z}$ in flapping CSs in the near-Earth re- 

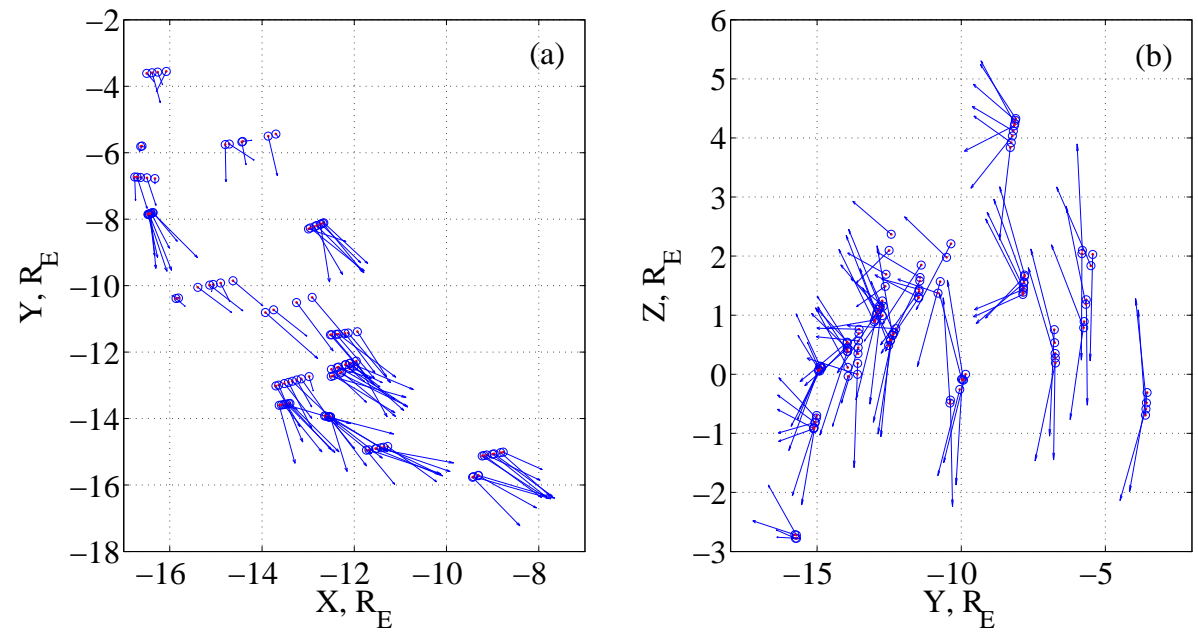

Figure 2. CS crossings (dots) and vectors $N$ in the $(X, Y)$ plane (a) and in the $(Y, Z)$ plane (b).
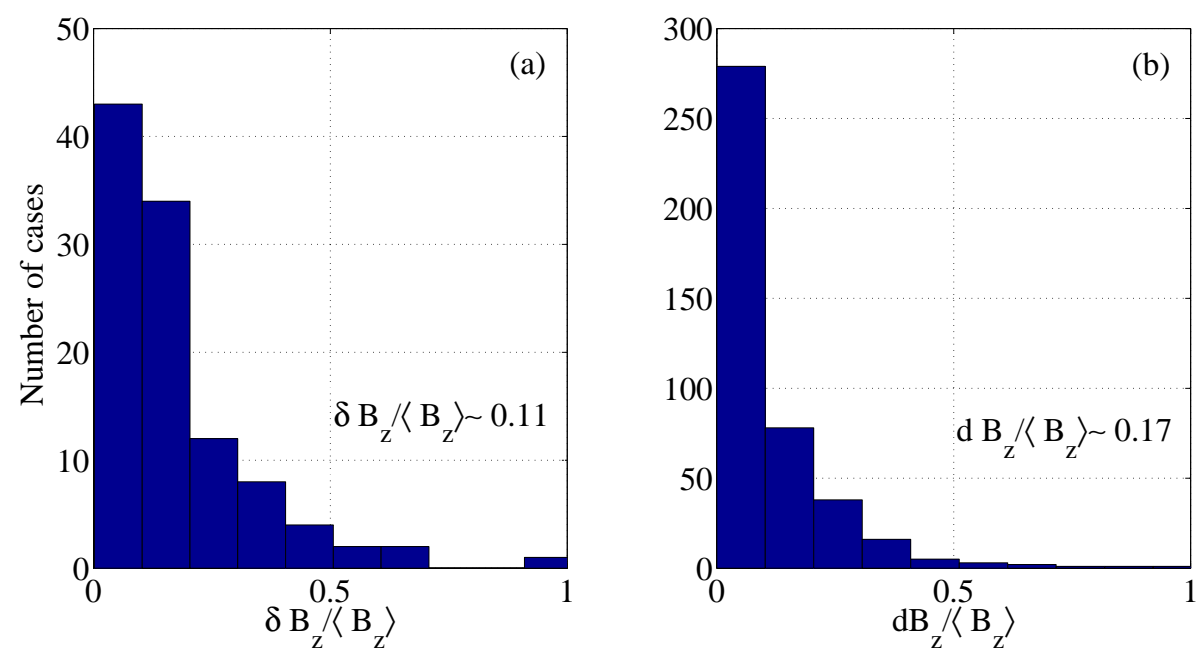

Figure 3. (a) Ratio of standard deviation $\delta B_{z}$ and magnetic field amplitude $\left\langle B_{z}\right\rangle$ averaged for different CS crossings within each series. (b) Ratio of standard deviation $\mathrm{d} B_{z}$ and magnetic field amplitude $\left\langle B_{z}\right\rangle$ averaged for each CS crossing.

gion, and that field lines in the CS centre are slipping with the dominant $B_{z}$ component (Petrukovich et al., 2008; Rong et al., 2011). These observations provide the important limitation for models of flapping waves (see Discussion).

Several theoretical models predict the substantial variations in $B_{z}$ with $x$ in oscillating CSs (Erkaev et al., 2009; Pritchett and Coroniti, 2010; Sitnov et al., 2014). The large distances between Cluster spacecraft allow us to investigate the homogeneity of the flapping wave within spatial scale around $10^{4} \mathrm{~km}$ (i.e. size of the Cluster tetrahedron). Figure $3 \mathrm{~b}$ shows the distribution of the standard deviation $\mathrm{d} B_{z}$ calculated for individual CS crossings by four spacecraft. This deviation is as small as $0.1 B_{z}$. Therefore, we could not find any significant variations in $B_{z}$ within the spatial scale of spacecraft separation. Moreover, for all observed CSs, the $l$ directions calculated for different spacecraft coincide. Thus, we can conclude that flapping CSs in the near-Earth magnetotail are more or less uniform in the $(X, Y)$ plane within the spatial scales about $1-2 R_{\mathrm{E}}$. This result confirms the previously reported THEMIS observations of large-scale flapping motion (Runov et al., 2009; Kubyshkina et al., 2014).

In the near-Earth magnetotail we expect to observe relatively strong gradients of $B_{z}$ along the $x$ axis (Kan and Baumjohann, 1990; Wang et al., 2009; Artemyev et al., 2013). The gradients $\partial B_{z} / \partial x, \partial B_{z} / \partial y$ and $\partial B_{z} / \partial r_{l}$, where $r_{l}=(\boldsymbol{r} \cdot \boldsymbol{l})$, of magnetic field in the current sheet centre is calculated for each crossing by means of the curlometer technique (Runov et al., 2005a) and presented in Fig. 4. The distribution of $\partial B_{z} / \partial x$ is centred around zero but has a significant tail with $\partial B_{z} / \partial x>0$. These positive strong gradients correspond to the quiet near-Earth magnetotail (Petrukovich et al., 2013). The dominance of weak gradients $\partial B_{z} / \partial x<$ 

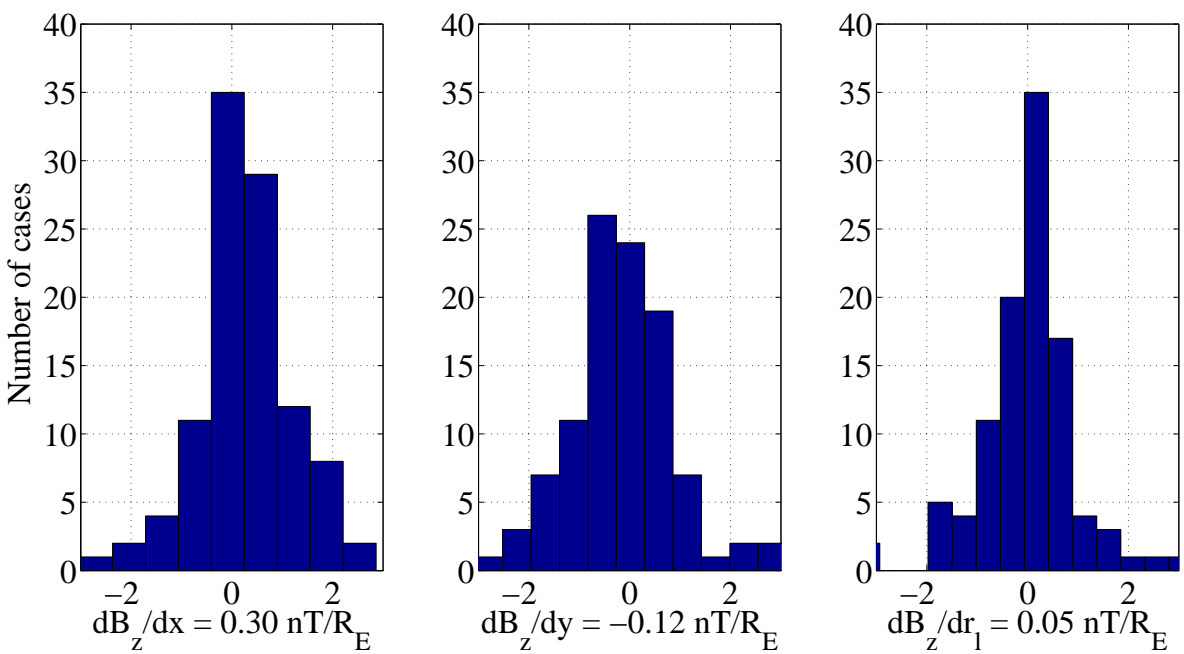

Figure 4. The gradients $\partial B_{z} / \partial x, \partial B_{z} / \partial y$ and $\partial B_{z} / \partial r_{l}$ of magnetic field $B_{z}$ in the CS centre for each CS crossing.
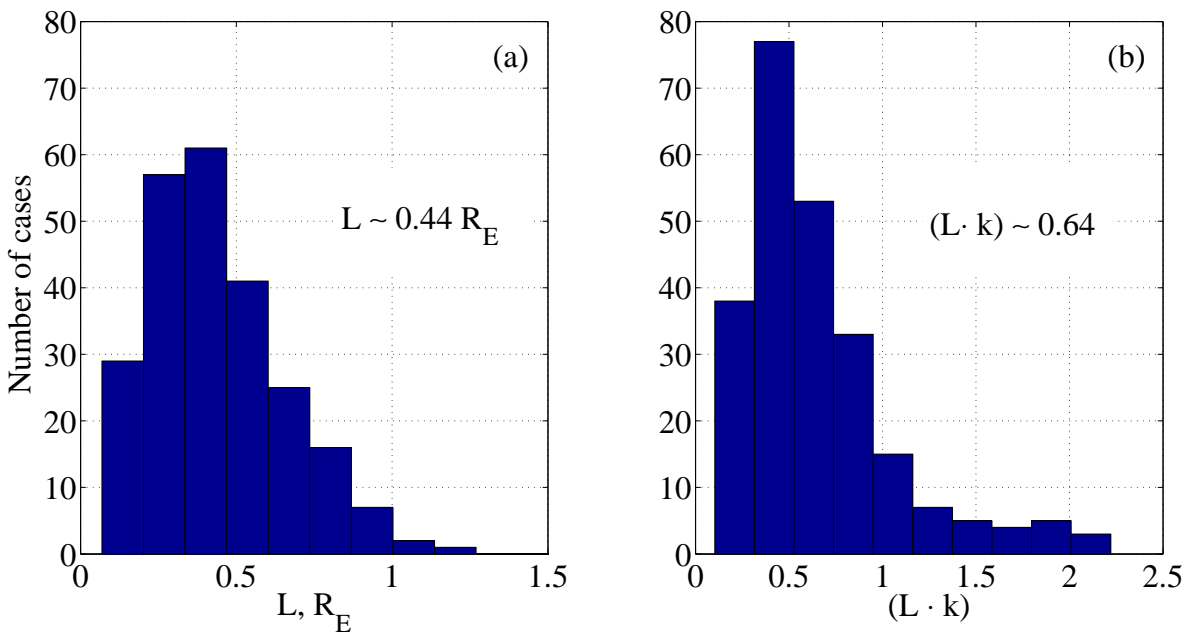

Figure 5. (a) The statistics of CS thickness $L$, calculated by $B_{0}$ and $j_{\text {tmg }}$ for each CS crossing. (b) The distribution $k L$ for CS thickness $L$ and wavevector $\boldsymbol{k}$.

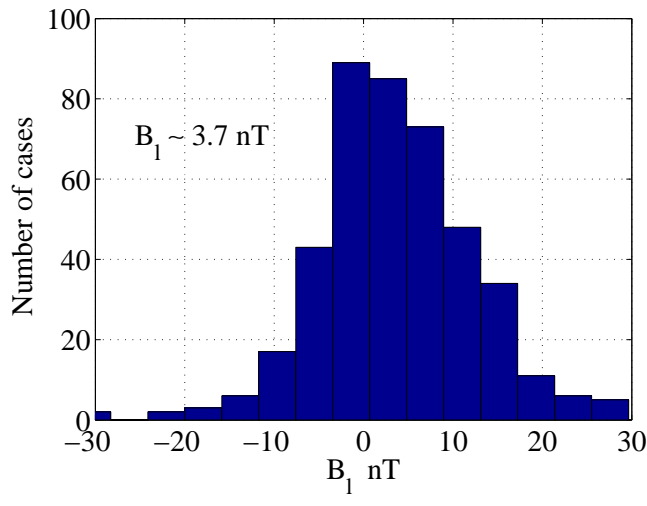

Figure 6. The position of the current density peak $j_{\text {tmg }}$ relative $B_{l}$ magnetic field.
$1 \mathrm{nT} / R_{\mathrm{E}}$ is attributed to observations at the flank magnetotail, where previous statistics show average values $\partial B_{z} / \partial x \sim$ $0.5 \mathrm{nT} / R_{\mathrm{E}}$ (Wang et al., 2009; Rong et al., 2014). However, the majority of observed CSs correspond to $\left|\partial B_{z} / \partial r_{l}\right|<0.2$ with an average value of about $\sim 0$. Thus, statistics of flapping CSs represent the subset of CSs with reduced $\partial B_{z} / \partial x$ gradients.

Estimates of $\partial B_{z} / \partial x$ allow us to compare the typical scale $L_{x} \sim B_{z}\left(\partial B_{z} / \partial x\right)^{-1}$ and the CS thickness $L$ (scale of magnetic field variation along the normal direction). Figure $5 \mathrm{a}$ shows that the average current sheet thickness $L$ is about $0.4 R_{\mathrm{E}}$. The average value of $\partial B_{z} / \partial r_{l}$ gradient derived from statistics shown in Fig. 4 is smaller than $0.1 \mathrm{nT} / R_{\mathrm{E}}$. Thus, the typical longitudinal size $L_{x}$ of tilted CS can be roughly estimated as $\sim 50 R_{\mathrm{E}}$ for $B_{z} \sim 5 \mathrm{nT}$. The CS configuration is determined by the parameter $\ell=2 L_{x} B_{0} /\left(B_{z} L\right)$ : for $\ell \sim 1$ 
we deal with the 2-D structure, while $\ell \gg 1$ corresponds to a quasi-1-D CS (Burkhart and Chen, 1993). In our case the estimates give $\ell \gg 1$ due to $L_{x} / L \sim 125$.

Figure 6 demonstrates the distribution of $B_{l}$ value corresponding to the peak value of the current density $j_{\text {tmg }}$. One can see that the average value of the distribution is positive $\left(B_{l} \sim 4 \mathrm{nT}\right)-$ i.e. there is a regular shift of the position of the current density peak relative to the $B_{l}$ reversal. This shift can be explained by the model of the kink CS deformation (Petrukovich et al., 2008; Rong et al., 2010). Moreover, we can suggest that the dominance of positive values of $B_{l}$ shift is due to the dominance of CS crossings with positive $z$ coordinates (i.e. the CS neutral plane is shifted relative to the geometrical neutral plane $z=0$ ). Due to the peculiarity of the Cluster orbit we do not have enough statistics to check whether this asymmetry changes the sign for $z<0$.

The distribution of ratio of parallel and total current densities is presented in Fig. 7. For almost all CSs $j_{\|}$represents more than $60 \%$ of the total current density. Moreover, cases with small $j_{\|}$correspond to the vertical flapping motion with $N$ parallel to $z$ axis, whereas in CSs with small $N_{z}$ component (i.e. CSs corresponding to flapping wave propagation toward the flank), almost all of the current is parallel to the magnetic field $\boldsymbol{B}$. This is the typical situation for tilted CSs, where the current density flows along the $z$ axis and $B_{z}$ is large enough (Petrukovich et al., 2003; Shen et al., 2008; Vasko et al., 2014). Strong $j_{z}$ current density results from deformation of the CS neutral plane (i.e. $j_{z} \sim \partial B_{x} / \partial y$ ) due to flapping motion (see models in Petrukovich et al., 2008; Rong et al., 2010). Moreover, to verify this result, we check that, for most of the CSs from our statistics, the value of $\boldsymbol{m} \times \boldsymbol{j} /|\boldsymbol{j}|$ is about 1 for $\boldsymbol{j}$ derived from the curlometer and $m$ derived from MVA and timing methods. Thus, in the nearEarth magnetotail the CS flapping motion generates of strong parallel currents.

Using the estimates of the CS flapping velocity $V_{N}$ and period $T$ (about $\sim 20 \mathrm{~min}$ ) we compare wavelength $2 \pi / k=$ $V_{N} T$ and CS thickness $L$. Figure $5 \mathrm{~b}$ shows that $k L$ is generally less than 1 (the averaged value is 0.64 ). Thus, we deal with long wavelength perturbations of CSs. The deformation of CS neutral plane likely does not change the interval CS structure on small scales, but redistributes current density between horizontal and vertical directions.

The directions of front prorogation $N$ are calculated from four-spacecraft data and have rather low accuracy. On the other hand, the directions of the $\boldsymbol{l}$ vectors are estimated quite well at each spacecraft and the large distances between spacecraft allow us to investigate the configuration of the front. Figure 8a and b show that the averaged gradient (calculated for each CS crossings) $\mathrm{d} \phi / \mathrm{d} x$ of the angle $\phi$ between the $l$ direction and $x$ axis is negative $\left(-2.5^{\circ} / R_{\mathrm{E}}\right)$ and $\mathrm{d} \phi / \mathrm{d} y$ is positive $\left(2.0^{\circ} / R_{\mathrm{E}}\right)(\phi=0$ when $l$ is parallel to $x$ axis and $\phi=-90^{\circ}$ when $l$ is parallel to $y$ axis). This means that the front configuration is most likely linear and azimuthally rotating than spherical and propagating from midnight, because

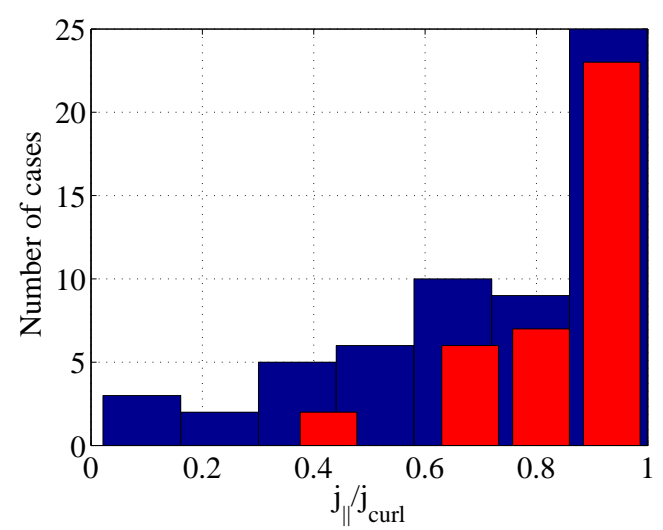

Figure 7. Ratio of currents $j_{\|}$parallel to the magnetic field and total currents $j$ (blue for all cases and red only for tilted CSs with $\left.\left|N_{z}\right|<0.7\right)$.

in the last case $\mathrm{d} \phi / \mathrm{d} y$ should be negative. Taking into account that the gradient $\partial B_{z} / \partial r_{l}$ is close to zero (see Fig. 4), we can suggest that (1) a midnight source of flapping waves runs them along constant levels of the $B_{z}$ field and (2) wave propagating results in the front rotation without a reconfiguration.

Figure 9 helps to compare a CS flapping velocity $V_{N}$ and typical plasma velocities, such as the drift velocity $V_{\mathrm{d}}=$ $j_{\mathrm{tmg}} /\left(e n_{\mathrm{e}}\right)$ and the projection of the ion velocity $\boldsymbol{V}_{\mathrm{i}}$ onto the $N$ direction, $V i_{\mathrm{pr}}$. The electron density $n_{\mathrm{e}}$ and ion velocity $\boldsymbol{V}_{\mathrm{i}}$ are taken from the PEACE experiment onboard C2 (Johnstone et al., 1997) and the CIS/HIA experiment onboard C1 (Rème et al., 2001) respectively. Figure 9a demonstrates that the CS flapping velocity $V_{N}$ is usually less than the drift velocity amplitude $V_{\mathrm{d}}=j_{\mathrm{tmg}} /\left(e n_{\mathrm{e}}\right)$ (the average value of their ratio is 0.33 and more than $95 \%$ of cases less then 1). Figure $9 \mathrm{~b}$ shows that the ratio of projection of ion bulk velocity and $V_{N}$ is about 1 (about $90 \%$ of all cases are distributed within the interval $[0.5 ; 2])$.

\section{Discussion}

The interesting property of the CS flapping motion in the near-Earth magnetotail is propagation towards the Earth at the flank (see Fig. 2). The earthward propagation means that the flapping waves generated at the midnight magnetotail can probably reach the flank boundary of the inner magnetosphere or the flank magnetopause. Periods of flapping motions range from a few minutes to half an hour. These periods are similar to periods of Pc5 pulsations in the inner magnetosphere (Jacobs et al., 1964; McPherron, 2005). Therefore, a flapping wave could transfer part of its energy for excitation of ULF waves that supplement other mechanisms of ULF wave generation by means of magnetotail dynamic processes (e.g. Runov et al., 2014; Panov et al., 2014). 

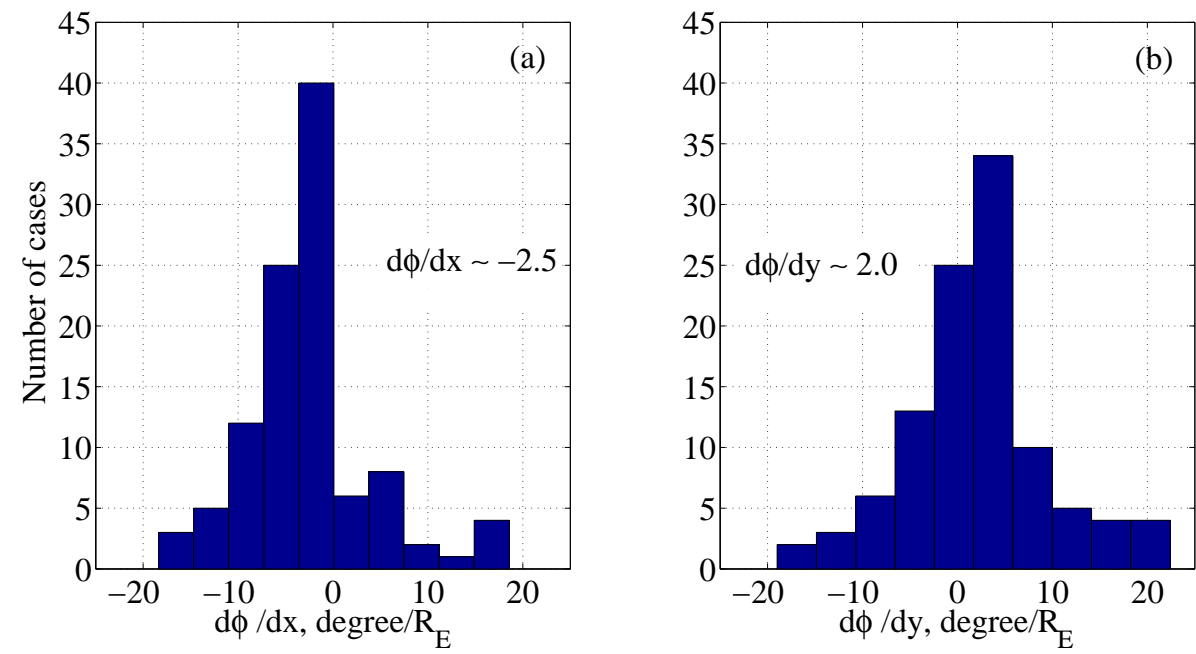

Figure 8. Gradients of the angle between the $l$ vector and $x$ axis: (a) $\mathrm{d} \phi / \mathrm{d} x$ and (b) $\mathrm{d} \phi / \mathrm{d} y$.
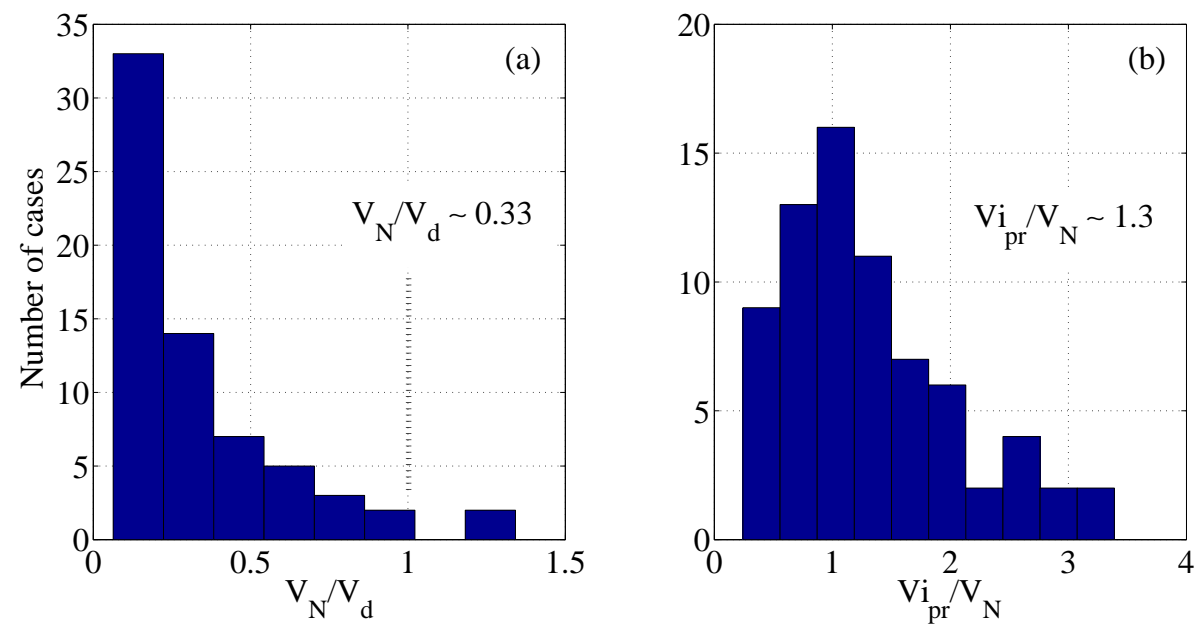

Figure 9. (a) Ratio of flapping wave velocity and drift velocity $V_{N} / V_{\mathrm{d}}$. (b) Ratio of ion bulk velocity and flapping wave velocity $V i_{\mathrm{pr}} / V_{N}$.

The connection between magnetotail dynamics and ionosphere processes involves the generation of parallel current systems in the near-Earth region. Statistics of current density distribution in flapping CSs (see Fig. 7) show that strong deformation of the CS neutral plane can generate fieldaligned currents. Amplitude of $j_{z}$ current density in tilted CSs reaches 5-15 nA m ${ }^{-2}$ (see Fig. 1 and statistics in Runov et al., 2005a; Vasko et al., 2014) and exceed dawn-dusk current density in quite magnetotail. If we assume that $j_{z}$ represents a new current system generated likely by field-aligned electron flows in tilted CSs, we can estimate corresponding amplitudes of parallel currents in flapping magnetotail. Flapping perturbations seem to have large scales in the $(X, Y)$ equatorial plane due to the efficient decrease in gradients $\partial / \partial x$ in flapping CSs (see Fig. 4). The typical scale of a CS along the $x$ axis is larger than (or comparable with) $\sim 2 R_{\mathrm{E}}$ (at such distances the tilted CSs are observed simultaneously by Cluster spacecraft in events collected in our statistics), while the scale along the $y$ axis for a tilted CS is $L \sim 0.3 R_{\mathrm{E}}$. Thus, a single tilted CS corresponds to the total current about $\sim 2 R_{\mathrm{E}} \times 0.3 R_{\mathrm{E}} \times 10 \mathrm{nA} \mathrm{m}^{-2} \sim 0.2 \mathrm{MA}$.

The relationship between CS thickness and wavenumber of perturbations $k=2 \pi / \lambda$ indicates that we deal with the long-wavelength deformations of the CS neutral plane (see Fig. 5b). This is a typical situation for various drift modes excited in the CS due to the relative motion (in the dawn-dusk direction) of charged particle flows (ions and electrons, or hot and background ions; see Daughton, 1999; Karimabadi et al., 2003a; Korovinskiy et al., 2015). Thus, a kink deformation of the neutral plane of flapping CSs can be induced by drift instabilities. Large spacecraft separation allows us to test predictions (or assumptions) of several existing models of flapping waves. A model of double-gradient instability (Erkaev et al., 2009) predicts that a relative pertur- 
bation of the $B_{z}$ component $\delta B_{z} / B_{z}$ should be comparable with a relative perturbation of the $B_{x}$ component. However, we observe a very weak perturbation of $\delta B_{z} / B_{z} \sim 0.2$ and a very strong perturbation of $\delta B_{x} / B_{x} \sim 1$. Moreover, we can compare periods of flapping waves (see Fig. 10) with predictions of double-gradient instability (Erkaev et al., 2009): $\quad \mathrm{d} T_{\text {model }} \approx 2 \pi / \sqrt{\left(\mathrm{d} B_{z} / \mathrm{d} x\right)\left(\mathrm{d} B_{x} / \mathrm{d} z\right) /\left(4 \pi m_{\mathrm{p}} n_{\mathrm{e}}\right)} \approx$ $2 \pi\left(4 \pi L^{2} m_{\mathrm{p}} n_{\mathrm{e}} / B_{0}^{2}\right)^{1 / 2} / \sqrt{2 \ell}$, where $m_{\mathrm{p}}$ is the proton mass and $\ell=2\left(B_{0} / L\right) /\left(\mathrm{d} B_{z} / \mathrm{d} x\right)$. For $\mathrm{d} B_{z} / \mathrm{d} x \approx \mathrm{d} B_{z} / \mathrm{d} r \approx$ $0.05 \mathrm{nT} / R_{\mathrm{E}}$ (see Fig. 4 ) and $L \approx 0.44 R_{\mathrm{E}}$ (see Fig. 5 ), we obtain $\mathrm{d} T_{\text {model }} \approx 3-10 \mathrm{~min}$ for average values of $B_{0} \approx 30 \mathrm{nT}$ and $n_{\mathrm{e}} \approx 0.3 \mathrm{~cm}^{-3}$. Observational periods of flapping motion vary between 9 and $25 \mathrm{~min}$ (see Fig. 10) - i.e. only fast oscillating CSs can be described by this model, whereas slowly oscillating CSs are too thin and intense to be described by the model of double-gradient instability (to have $\mathrm{d} T_{\text {model }} \approx 25$ min we need $L \approx 1.5 R_{\mathrm{E}}$ ). Ballooning/interchange instability can also run flapping-like waves with flankward propagation (Pritchett and Coroniti, 2010). However, this instability requires the significant gradient $\mathrm{d} B_{z} / \mathrm{d} x<0$, whereas we find only a weak (a value around zero) or positive gradient $\mathrm{d} B_{z} / \mathrm{d} x$ (see Fig. 4). Kink modes of CS instability (Daughton, 1999; Karimabadi et al., 2003a; Zelenyi et al., 2009) predict the flapping wave velocity about a drift velocity (due to strong diamagnetic drifts in the initial CS). Configuration of titled CSs assumes that current carrying particles (i.e. relative velocity of ions and electrons along the current density direction) flow almost along magnetic field lines, whereas CS flapping motion is in the transverse direction. Thus, we can estimate both ion drift velocity $V_{\mathrm{i}}$ (i.e. velocity along the dawn-dusk direction) and current carrier velocity $V_{\mathrm{d}}$ (i.e. ratio of the current density and plasma density amplitudes). Our observations show that flapping velocity is comparable with observed ion bulk velocity $V_{\mathrm{i}}$ and is much smaller than $V_{\mathrm{d}}$ (see Fig. 9). Therefore, kink modes of CS instability can explain flapping wave propagation but cannot describe the dominance of parallel currents with large $V_{\mathrm{d}}$ (most models of kink waves consider zero or vanishing $B_{z}$; e.g. Daughton, 1999; Karimabadi et al., 2003a; Zelenyi et al., 2009). Finally, we come to the puzzling conclusion that all three different instabilities (double-gradient, ballooning/interchange, and kink) meet difficulties in the explanation of observed flapping waves. Thus, further investigation of CS motion with significant parallel currents should be performed for explanation of observed flapping waves. Such parallel currents are likely carried by electrons (as was suggested and tested by Runov et al., 2006; Vasko et al., 2014).

\section{Conclusions}

In this paper we present the statistics of flapping CSs observed in the near-Earth magnetotail. The main our findings can be summarised as follows:

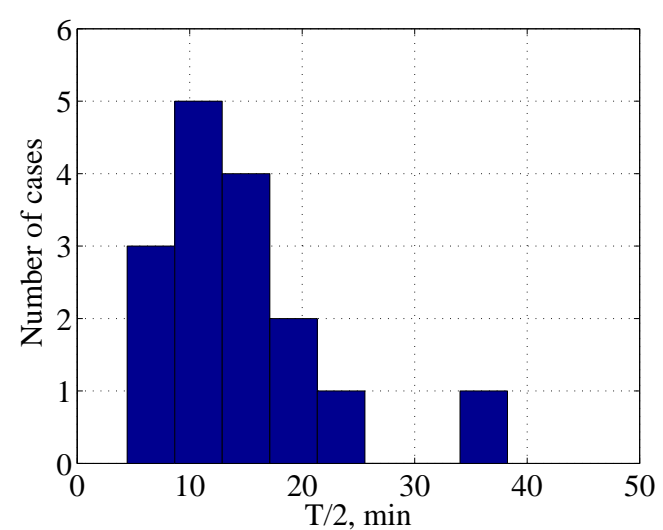

Figure 10. Distribution of flapping wave periods for our dataset.

- Despite the relatively strong gradients $\partial B_{z} / \partial x$ in the background CS in the near-Earth tail (Kan and Baumjohann, 1990; Artemyev et al., 2013; Rong et al., 2014), this gradient is significantly reduced in flapping CSs $\left(\sim 0.2 \mathrm{nT} / R_{\mathrm{E}}\right)$. Moreover, a weak-gradient $\mathrm{d} B_{z} / \mathrm{d} x$ found in the flapping near-Earth magnetotail questions models of double-gradient and ballooning/interchange instabilities as main candidates for excitation of flapping waves (Erkaev et al., 2009; Pritchett and Coroniti, 2010).

- The velocity of flapping wave probation is close to ion bulk velocity $V_{\mathrm{i}}$ and is much smaller than current carrier velocity $V_{\mathrm{d}}=j_{\mathrm{tmg}} /\left(e n_{\mathrm{e}}\right)$. The wavelength of flapping motion is larger than CS thickness $(k L<1)$. These observations point to a drift nature of flapping waves.

- Flapping waves in the near-Earth magnetotail generate strong parallel currents with an amplitude of about $\sim 0.2 \mathrm{MA}$ and have a transverse spatial-scale $L$ smaller than the wavelength (i.e. typical distance between neighbourhood structures) and typical periods of about $\sim 20 \mathrm{~min}$.

\section{Data availability}

All data were downloaded from Cluster Science Archive (ESA, 2016) (http://www.cosmos.esa.int/web/csa).

Acknowledgements. We are thankful to I. Y. Vasko for useful discussions. The authors would like to acknowledge the Cluster Active Archive, Cluster Science Archive, and Cluster instrument teams, in particular the FGM team for excellent data. The work of E. V. Yushkov, A. V. Artemyev, and A. A. Petrukovich was supported by the Russian Foundation for Basic Research (project no. 14-05-91000). The work of R. Nakamura was supported by the Austrian Science Fund (FWF I2016-N20).

The topical editor, E. Roussos, thanks two anonymous referees for help in evaluating this paper. 


\section{References}

Angelopoulos, V., McFadden, J. P., Larson, D., Carlson, C. W., Mende, S. B., Frey, H., Phan, T., Sibeck, D. G., Glassmeier, K., Auster, U., Donovan, E., Mann, I. R., Rae, I. J., Russell, C. T., Runov, A., Zhou, X., and Kepko, L.: Tail Reconnection Triggering Substorm Onset, Science, 321, 931-935, doi:10.1126/science.1160495, 2008.

Artemyev, A. V., Petrukovich, A. A., Nakamura, R., and Zelenyi, L. M.: Profiles of electron temperature and $B_{z}$ along Earth's magnetotail, Ann. Geophys., 31, 1109-1114, doi:10.5194/angeo-311109-2013, 2013.

Artemyev, A. V., Petrukovich, A. A., Nakamura, R., and Zelenyi, L. M.: Two-dimensional configuration of the magnetotail current sheet: THEMIS observations, Geophys. Res. Lett., 42, 36623667, doi:10.1002/2015GL063994, 2015.

Baker, D. N., Pulkkinen, T. I., Angelopoulos, V., Baumjohann, W., and McPherron, R. L.: Neutral line model of substorms: Past results and present view, J. Geophys. Res., 101, 12975-13010, doi:10.1029/95JA03753, 1996.

Baumjohann, W., Roux, A., Le Contel, O., Nakamura, R., Birn, J., Hoshino, M., Lui, A. T. Y., Owen, C. J., Sauvaud, J.-A., Vaivads, A., Fontaine, D., and Runov, A.: Dynamics of thin current sheets: Cluster observations, Ann. Geophys., 25, 13651389, doi:10.5194/angeo-25-1365-2007, 2007.

Burkhart, G. R. and Chen, J.: Particle motion in x-dependent Harris-like magnetotail models, J. Geophys. Res., 98, 89-97, doi:10.1029/92JA01528, 1993.

Daughton, W.: The unstable eigenmodes of a neutral sheet, Phys. Plasmas, 6, 1329-1343, doi:10.1063/1.873374, 1999.

Dunlop, M. W., Balogh, A., Glassmeier, K.-H., and Robert, P.: Four-point Cluster application of magnetic field analysis tools: The Curlometer, J. Geophys. Res., 107, 1384, doi:10.1029/2001JA005088, 2002.

Erkaev, N. V., Semenov, V. S., Kubyshkin, I. V., Kubyshkina, M. V., and Biernat, H. K.: MHD model of the flapping motions in the magnetotail current sheet, J. Geophys. Res., 114, A03206, doi:10.1029/2008JA013728, 2009.

ESA: Cluster Science Archive, available at: http://www.cosmos.esa. int/web/csa, last access: 7 September 2016.

Jacobs, J. A., Kato, Y., Matsushita, S., and Troitskaya, V. A.: Classification of Geomagnetic Micropulsations, J. Geophys. Res., 69, 180-181, doi:10.1029/JZ069i001p00180, 1964.

Johnstone, A. D., Alsop, C., Burge, S., Carter, P. J., Coates, A. J., Coker, A. J., Fazakerley, A. N., Grande, M., Gowen, R. A., Gurgiolo, C., Hancock, B. K., Narheim, B., Preece, A., Sheather, P. H., Winningham, J. D., and Woodliffe, R. D.: Peace: a Plasma Electron and Current Experiment, Space Sci. Rev., 79, 351-398, doi:10.1023/A:1004938001388, 1997.

Kan, J. R. and Baumjohann, W.: Isotropized magnetic-moment equation of state for the central plasma sheet, Geophys. Res. Lett., 17, 271-274, doi:10.1029/GL017i003p00271, 1990.

Karimabadi, H., Daughton, W., Pritchett, P. L., and Krauss-Varban, D.: Ion-ion kink instability in the magnetotail: 1. Linear theory, J. Geophys. Res., 108, 1400, doi:10.1029/2003JA010026, $2003 \mathrm{a}$.

Karimabadi, H., Pritchett, P. L., Daughton, W., and KraussVarban, D.: Ion-ion kink instability in the magnetotail: 2. Three-dimensional full particle and hybrid simulations and comparison with observations, J. Geophys. Res., 108, 1401, doi:10.1029/2003JA010109, 2003b.
Korovinskiy, D. B., Divin, A. V., Erkaev, N. V., Semenov, V. S., Artemyev, A. V., Ivanova, V. V., Ivanov, I. B., Lapenta, G., Markidis, S., and Biernat, H. K.: The double-gradient magnetic instability: Stabilizing effect of the guide field, Phys. Plasmas, 22, 012904, doi:10.1063/1.4905706, 2015.

Kubyshkina, D. I., Sormakov, D. A., Sergeev, V. A., Semenov, V. S., Erkaev, N. V., Kubyshkin, I. V., Ganushkina, N. Y., and Dubyagin, S. V.: How to distinguish between kink and sausage modes in flapping oscillations?, J. Geophys. Res., 119, 3002 3015, doi:10.1002/2013JA019477, 2014.

Lui, A. T. Y.: Potential Plasma Instabilities For Substorm Expansion Onsets, Space Sci. Rev., 113, 127-206, doi:10.1023/B:SPAC.0000042942.00362.4e, 2004.

McPherron, R. L.: Magnetic Pulsations: Their Sources and Relation to Solar Wind and Geomagnetic Activity, Surv. Geophys., 26, 545-592, doi:10.1007/s10712-005-1758-7, 2005.

Nakamura, R., Retinò, A., Baumjohann, W., Volwerk, M., Erkaev, N., Klecker, B., Lucek, E. A., Dandouras, I., André, M., and Khotyaintsev, Y.: Evolution of dipolarization in the nearEarth current sheet induced by Earthward rapid flux transport, Ann. Geophys., 27, 1743-1754, doi:10.5194/angeo-27-17432009, 2009.

Panov, E. V., Nakamura, R., Baumjohann, W., Kubyshkina, M. G., Artemyev, A. V., Sergeev, V. A., Petrukovich, A. A., Angelopoulos, V., Glassmeier, K.-H., McFadden, J. P., and Larson, D.: Kinetic ballooning/interchange instability in a bent plasma sheet, J. Geophys. Res., 117, A06228, doi:10.1029/2011JA017496, 2012a.

Panov, E. V., Sergeev, V. A., Pritchett, P. L., Coroniti, F. V., Nakamura, R., Baumjohann, W., Angelopoulos, V., Auster, H. U., and McFadden, J. P.: Observations of kinetic ballooning/interchange instability signatures in the magnetotail, Geophys. Res. Lett., 39, L08110, doi:10.1029/2012GL051668, 2012b.

Panov, E. V., Baumjohann, W., Nakamura, R., Kubyshkina, M. V., Glassmeier, K.-H., Angelopoulos, V., Petrukovich, A. A., and Sergeev, V. A.: Period and damping factor of $\mathrm{Pi} 2$ pulsations during oscillatory flow braking in the magnetotail, J. Geophys. Res., 119, 4512-4520, doi:10.1002/2013JA019633, 2014.

Paschmann, G. and Schwartz, S. J.: ISSI Book on Analysis Methods for Multi-Spacecraft Data, vol. 449 of ESA Special Publication, 2000.

Petrukovich, A. A., Baumjohann, W., Nakamura, R., Balogh, A., Mukai, T., Glassmeier, K.-H., Reme, H., and Klecker, B.: Plasma sheet structure during strongly northward IMF, J. Geophys. Res., 108, 1258, doi:10.1029/2002JA009738, 2003.

Petrukovich, A. A., Zhang, T. 1., Baumjohann, W., Nakamura, R., Runov, A., Balogh, A., and Carr, C.: Oscillatory magnetic flux tube slippage in the plasma sheet, Ann. Geophys., 24, 16951704, doi:10.5194/angeo-24-1695-2006, 2006.

Petrukovich, A. A., Baumjohann, W., Nakamura, R., Runov, A., Balogh, A., and Rème, H.: Thinning and stretching of the plasma sheet, J. Geophys. Res., 112, 10213, doi:10.1029/2007JA012349, 2007.

Petrukovich, A. A., Baumjohann, W., Nakamura, R., and Runov, A.: Formation of current density profile in tilted current sheets, Ann. Geophys., 26, 3669-3676, doi:10.5194/angeo-26-36692008, 2008.

Petrukovich, A. A., Artemyev, A. V., Nakamura, R., Panov, E. V., and Baumjohann, W.: Cluster observations of $\mathrm{d} B_{z} / \mathrm{d} x$ during 
growth phase magnetotail stretching intervals, J. Geophys. Res., 118, 5720-5730, doi:10.1002/jgra.50550, 2013.

Pritchett, P. L. and Coroniti, F. V.: A kinetic ballooning/interchange instability in the magnetotail, J. Geophys. Res., 115, A06301, doi:10.1029/2009JA014752, 2010.

Pritchett, P. L. and Coroniti, F. V.: Plasma sheet disruption by interchange-generated flow intrusions, Geophys. Res. Lett., 381, L10102, doi:10.1029/2011GL047527, 2011.

Rème, H., Aoustin, C., Bosqued, J. M., Dandouras, I., Lavraud, B., Sauvaud, J. A., Barthe, A., Bouyssou, J., Camus, Th., Coeur-Joly, O., Cros, A., Cuvilo, J., Ducay, F., Garbarowitz, Y., Medale, J. L., Penou, E., Perrier, H., Romefort, D., Rouzaud, J., Vallat, C., Alcaydé, D., Jacquey, C., Mazelle, C., d'Uston, C., Möbius, E., Kistler, L. M., Crocker, K., Granoff, M., Mouikis, C., Popecki, M., Vosbury, M., Klecker, B., Hovestadt, D., Kucharek, H., Kuenneth, E., Paschmann, G., Scholer, M., Sckopke, N., Seidenschwang, E., Carlson, C. W., Curtis, D. W., Ingraham, C., Lin, R. P., McFadden, J. P., Parks, G. K., Phan, T., Formisano, V., Amata, E., Bavassano-Cattaneo, M. B., Baldetti, P., Bruno, R., Chionchio, G., Di Lellis, A., Marcucci, M. F., Pallocchia, G., Korth, A., Daly, P. W., Graeve, B., Rosenbauer, H., Vasyliunas, V., McCarthy, M., Wilber, M., Eliasson, L., Lundin, R., Olsen, S., Shelley, E. G., Fuselier, S., Ghielmetti, A. G., Lennartsson, W., Escoubet, C. P., Balsiger, H., Friedel, R., Cao, J.-B., Kovrazhkin, R. A., Papamastorakis, I., Pellat, R., Scudder, J., and Sonnerup, B.: First multispacecraft ion measurements in and near the Earth's magnetosphere with the identical Cluster ion spectrometry (CIS) experiment, Ann. Geophys., 19, 1303-1354, doi:10.5194/angeo19-1303-2001, 2001.

Rong, Z. J., Shen, C., Petrukovich, A. A., Wan, W. X., and Liu, Z. X.: The analytic properties of the flapping current sheets in the earth magnetotail, Planet. Space Sci., 58, 1215-1229, doi:10.1016/j.pss.2010.04.016, 2010.

Rong, Z. J., Wan, W. X., Shen, C., Li, X., Dunlop, M. W., Petrukovich, A. A., Zhang, T. L., and Lucek, E.: Statistical survey on the magnetic structure in magnetotail current sheets, J. Geophys. Res.-Space, 116, A09218, doi:10.1029/2011JA016489, 2011.

Rong, Z. J., Wan, W. X., Shen, C., Petrukovich, A. A., Baumjohann, W., Dunlop, M. W., and Zhang, Y. C.: Radial distribution of magnetic field in earth magnetotail current sheet, Planet. Space Sci., 103, 273-285, doi:10.1016/j.pss.2014.07.014, 2014.

Rong, Z. J., Barabash, S., Stenberg, G., Futaana, Y., Zhang, T., Wan, W. X., Wei, Y., and Wang, X. D.: Technique for diagnosing the flapping motion of magnetotail current sheets based on singlepoint magnetic field analysis, J. Geophys. Res., 120, 3462-3474, doi:10.1002/2014JA020973, 2015.

Runov, A., Sergeev, V. A., Baumjohann, W., Nakamura, R., Apatenkov, S., Asano, Y., Volwerk, M., Vörös, Z., Zhang, T. L., Petrukovich, A., Balogh, A., Sauvaud, J.-A., Klecker, B., and Rème, H.: Electric current and magnetic field geometry in flapping magnetotail current sheets, Ann. Geophys., 23, 1391-1403, doi:10.5194/angeo-23-1391-2005, 2005a.

Runov, A., Sergeev, V. A., Nakamura, R., Baumjohann, W., Zhang, T. L., Asano, Y., Volwerk, M., Vörös, Z., Balogh, A., and Rème, H.: Reconstruction of the magnetotail current sheet structure using multi-point Cluster measurements, Planet. Space Sci., 53, 237-243, doi:10.1016/j.pss.2004.09.049, 2005b.
Runov, A., Sergeev, V. A., Nakamura, R., Baumjohann, W., Apatenkov, S., Asano, Y., Takada, T., Volwerk, M., Vörös, Z., Zhang, T. L., Sauvaud, J.-A., Rème, H., and Balogh, A.: Local structure of the magnetotail current sheet: 2001 Cluster observations, Ann. Geophys., 24, 247-262, doi:10.5194/angeo-24-2472006, 2006

Runov, A., Angelopoulos, V., Sergeev, V. A., Glassmeier, K.-H., Auster, U., McFadden, J., Larson, D., and Mann, I.: Global properties of magnetotail current sheet flapping: THEMIS perspectives, Ann. Geophys., 27, 319-328, doi:10.5194/angeo-27-3192009, 2009.

Runov, A., Angelopoulos, V., and Zhou, X.-Z.: Multipoint observations of dipolarization front formation by magnetotail reconnection, J. Geophys. Res., 117, A05230, doi:10.1029/2011JA017361, 2012.

Runov, A., Sergeev, V. A., Angelopoulos, V., Glassmeier, K.H., and Singer, H. J.: Diamagnetic oscillations ahead of stopped dipolarization fronts, J. Geophys. Res., 119, 1643-1657, doi:10.1002/2013JA019384, 2014.

Schindler, K.: Physics of Space Plasma Activity, Cambridge University Press, doi:10.2277/0521858976, 2006.

Sergeev, V., Angelopoulos, V., Carlson, C., and Sutcliffe, P.: Current sheet measurements within a flapping plasma sheet, J. Geophys. Res., 103, 9177-9188, doi:10.1029/97JA02093, 1998.

Sergeev, V., Runov, A., Baumjohann, W., Nakamura, R., Zhang, T. L., Balogh, A., Louarnd, P., Sauvaud, J., and Reme, H.: Orientation and propagation of current sheet oscillations, Geophys. Res. Lett., 31, L05807, doi:10.1029/2003GL019346, 2004.

Sergeev, V. A., Sormakov, D. A., Apatenkov, S. V., Baumjohann, W., Nakamura, R., Runov, A. V., Mukai, T., and Nagai, T.: Survey of large-amplitude flapping motions in the midtail current sheet, Ann. Geophys., 24, 2015-2024, doi:10.5194/angeo-242015-2006, 2006.

Sharma, A. S., Nakamura, R., Runov, A., Grigorenko, E. E., Hasegawa, H., Hoshino, M., Louarn, P., Owen, C. J., Petrukovich, A., Sauvaud, J.-A., Semenov, V. S., Sergeev, V. A., Slavin, J. A., Sonnerup, B. U. Ö., Zelenyi, L. M., Fruit, G., Haaland, S., Malova, H., and Snekvik, K.: Transient and localized processes in the magnetotail: a review, Ann. Geophys., 26, 9551006, doi:10.5194/angeo-26-955-2008, 2008.

Shen, C., Rong, Z. J., Li, X., Dunlop, M., Liu, Z. X., Malova, H. V., Lucek, E., and Carr, C.: Magnetic configurations of the tilted current sheets in magnetotail, Ann. Geophys., 26, 3525-3543, doi:10.5194/angeo-26-3525-2008, 2008.

Shen, C., Rong, Z. J., Dunlop, M. W., Ma, Y. H., Li, X., Zeng, G., Yan, G. Q., Wan, W. X., Liu, Z. X., Carr, C. M., and Rème, H.: Spatial gradients from irregular, multiple-point spacecraft configurations, J. Geophys. Res.-Space, 117, A11207, doi:10.1029/2012JA018075, 2012.

Sitnov, M. I., Swisdak, M., Guzdar, P. N., and Runov, A.: Structure and dynamics of a new class of thin current sheets, J. Geophys. Res., 111, 8204, doi:10.1029/2005JA011517, 2006.

Sitnov, M. I., Merkin, V. G., Swisdak, M., Motoba, T., Buzulukova, N., Moore, T. E., Mauk, B. H., and Ohtani, S.: Magnetic reconnection, buoyancy, and flapping motions in magnetotail explosions, J. Geophys. Res., 119, 7151-7168, doi:10.1002/2014JA020205, 2014. 
Treumann, R. A. and Baumjohann, W.: Collisionless magnetic reconnection in space plasmas, Front. Phys., 1, 1-34, doi:10.3389/fphy.2013.00031, 2013.

Vasko, I. Y., Artemyev, A. V., Petrukovich, A. A., Nakamura, R., and Zelenyi, L. M.: The structure of strongly tilted current sheets in the Earth magnetotail, Ann. Geophys., 32, 133-146, doi:10.5194/angeo-32-133-2014, 2014.

Wang, C., Lyons, L. R., Wolf, R. A., Nagai, T., Weygand, J. M., and Lui, A. T. Y.: Plasma sheet $P V^{5 / 3}$ and $n V$ and associated plasma and energy transport for different convection strengths and AE levels, J. Geophys. Res., 114, A00D02, doi:10.1029/2008JA013849, 2009.

Wygant, J. R., Cattell, C. A., Lysak, R., Song, Y., Dombeck, J., McFadden, J., Mozer, F. S., Carlson, C. W., Parks, G., Lucek, E. A., Balogh, A., Andre, M., Reme, H., Hesse, M., and Mouikis, C.: Cluster observations of an intense normal component of the electric field at a thin reconnecting current sheet in the tail and its role in the shock-like acceleration of the ion fluid into the separatrix region, J. Geophys. Res., 110, A09206, doi:10.1029/2004JA010708, 2005.
Zelenyi, L. and Artemyev, A.: Mechanisms of Spontaneous Reconnection: From Magnetospheric to Fusion Plasma, Space Sci. Rev., 178, 441-457, 2013.

Zelenyi, L. M., Artemyev, A. V., Petrukovich, A. A., Nakamura, R., Malova, H. V., and Popov, V. Y.: Low frequency eigenmodes of thin anisotropic current sheets and Cluster observations, Ann. Geophys., 27, 861-868, doi:10.5194/angeo-27-861-2009, 2009.

Zhang, T. L., Baumjohann, W., Nakamura, R., Balogh, A., and Glassmeier, K.: A wavy twisted neutral sheet observed by CLUSTER, Geophys. Res. Lett., 29, 190000, doi:10.1029/2002GL015544, 2002.

Zhang, T. L., Nakamura, R., Volwerk, M., Runov, A., Baumjohann, W., Eichelberger, H. U., Carr, C., Balogh, A., Sergeev, V., Shi, J. K., and Fornacon, K.-H.: Double Star/Cluster observation of neutral sheet oscillations on 5 August 2004, Ann. Geophys., 23, 2909-2914, doi:10.5194/angeo-23-2909-2005, 2005. 